\title{
Principles Governing DNA Methylation during Neuronal Lineage and Subtype Specification
}

\author{
(DAli Sharma, ${ }^{\star}$ Shifra Liba Klein, ${ }^{\star}$ Luendreo Barboza, Niraj Lodhi, and Miklos Toth \\ Department of Pharmacology, Weill Cornell Medical College, New York, New York 10065
}

\begin{abstract}
Although comprehensively described during early neuronal development, the role of DNA methylation/demethylation in neuronal lineage and subtype specification is not well understood. By studying two distinct neuronal progenitors as they differentiate to principal neurons in mouse hippocampus and striatum, we uncovered several principles governing neuronal DNA methylation during brain development. (1) The program consists of three stages: an initial genome-wide methylation during progenitor proliferation is followed by loss of methylation during the transition of regional progenitors to "young" hippocampal/striatal neurons, which is then reversed by gain in methylation during maturation to subtype-specific neurons. (2) At the first two stages, gain and loss of methylation are limited to CpGs, whereas during the third maturation stage, methylation also occurs at non- $\mathrm{CpG}$ sites in both lineages. (3) Methylation/demethylation, similar to transcription, are initially highly similar in the two lineages, whereas diversification in methylation and transcription during maturation creates subtype-specific methylation differences. (4) Initially, methylation targets all genomic locations, whereas later, during early and late differentiation, the preferred targets are intronic/intergenic sequences with enhancer-like activity. (5) Differentially methylated genes are enriched in sequential neurodevelopmental functions (such as progenitor proliferation, migration, neuritogenesis, and synaptic transmission); upregulated genes represent current and consecutive stage-specific functions, and downregulated genes represent preceding functions that are no longer required. The main conclusion of our work is that the neuronal methylation/demethylation program is predominantly developmental with minimal lineage specificity, except in the final stage of development when neuron subtype-specific differences also emerge.
\end{abstract}

Key words: DNA methylation; hippocampus; neuronal development; neuronal progenitors; neuronal specification; striatum

Significance Statement

Our work is the first to describe a set of relatively simple rules that govern DNA methylation and demethylation in neuronal development in vivo. By dividing neurodevelopment to three major stages and applying rules to each of them, we created a matrix that comprehensively describes DNA methylation/demethylation events in two neuronal lineages, with a total of 10 cell types spanning the entire neurodevelopment. Beyond increasing our understanding of the epigenetic regulation of normal development, our work will be useful in deciphering how environmental perturbations, such as gestational toxins, drugs, stress, infection, and offspring neglect/maltreatment, interfere with the developmental methylation program.

\section{Introduction}

An important question in neuroscience is to understand how neuronal lineages, and the large number of neuronal subtypes,

Received Nov. 9, 2015; revised Dec. 18, 2015; accepted Dec. $22,2015$.

Author contributions: S.L.K. and M.T. designed research; A.S., S.L.K., L.B., and N.L. performed research; A.S., S.L.K., and M.T. analyzed data; M.T. wrote the paper.

We are grateful for support from Grant R01 MH094720 from the National Institute of Health to M.T. We thank L. Skrabanek for her computational guidance and the Weill Cornell Medical College Epigenetic Core Facility for Illumina sequencing. We are grateful for Stewart Anderson (University of Pennsylvania, Philadelphia, PA) for his advice on brain microdissection. We also thank L. Parada (University of Texas Southwestern Medical Center, Dallas, TX) for the nestin-CreERT2 mouse line and Riken Bio Resource Center (Koyadai, Tbukuba, Ibaraki, Japan) for the mice with floxed Dnmt3a alleles. The authors declare no competing financial interests.

*A.S. and S.L.K. contributed equally to this work.

Correspondence should be addressed to Miklos Toth at the above address. E-mail: mtoth@med.cornell.edu. DOI:10.1523/JNEUROSCI.4037-15.2016

Copyright $\odot 2016$ the authors $\quad 0270-6474 / 16 / 361711-12 \$ 15.00 / 0$ are established in the CNS during development and how this program is perturbed in neurodevelopmental disorders. Neuronal development is driven by a transcriptional program consisting of morphogens, their downstream intracellular signaling pathways, and associated transcription factors. Accessibility of these factors to DNA is regulated by epigenetic mechanisms such as DNA methylation (Moore et al., 2013). An alternative model is that DNA methylation is secondary to regulation that cooperates with other factors to solidify the regulatory state (Stadler et al., 2011; Thurman et al., 2012).

Compared to DNA binding proteins and cofactors, relatively little is known regarding the role of DNA methylation in neuronal development. Studies with neuronal progenitors, differentiated in vitro from embryonic stem cells (ESCs), showed that pluripotency genes are methylated and repressed whereas a subset of genes, which 
are active in terminally differentiated neurons, become hypomethylated and bivalent (Mohn et al., 2008; Hirabayashi and Gotoh, 2010). Another report described hypomethylation at enhancer-like elements and increased expression at nearby genes in similar neuronal progenitors (Stadler et al., 2011). However, an in vitro differentiation system may not capture the complexities of lineage and neuronal subtype diversification and corresponding DNA methylation changes occurring in vivo. Finally, Lister et al., 2013 studied DNA methylation during mouse development, but in a mixed population of telencephalic neurons. Therefore, our aim was to determine DNA methylation differences between two prototypical neurons, hippocampal glutamatergic and striatal GABAergic, and their precursors at single-base resolution to assess the contribution of DNA methylation to neuronal development and subtype specification.

Hippocampal and striatal neurons differ in fundamental characteristics, including their origin, neurotransmitter identify, and function. Hippocampal principal neurons, which include CA1 and CA3 pyramidal neurons as well as dentate gyrus (DG) granule cells (GCs), derive from the most medial domain of the dorsal, whereas striatal projection neurons (medium spiny neurons or MSNs) derive from the ventral telencephalon. Whereas hippocampal neurons are involved in spatial learning/memory and navigation, MSNs are associated with coordination of movement (dorsal or dMSNs) and reward processes (ventral or vMSNs). The hippocampal circuit is often implicated in epileptic seizures, and hippocampal neurons are one of the first neuronal subtypes affected in Alzheimer's disease. In contrast, MSNs degenerate in Huntington's disease and receive projections from dopamine neurons that are lost in Parkinson's disease.

Differentiation of ESCs to neuron-restricted neuronal progenitors and then to subtype-specific neurons in the CNS is a gradual process of diversification. ESCs in the inner cell mass of the embryonic day 3.5 (E3.5) blastocyst undergo progressive fate restriction and sequentially give rise to tissue-specific multipotent progenitor cells, including hippocampal progenitors (HPs) and striatal progenitors (SPs), in the E9.5-E10.5 telencephalon (Fig. 1A, B, developmental stage 1). HPs are derived from the epithelium of the ventricular germinal layer, whereas SPs are derived from the lateral ganglionic eminence (LGE; Bayer, 1980; Deacon et al., 1994; Wilson and Rubenstein, 2000). The regional specification of these progenitors is regulated by morphogens produced in patterning centers (Wnt dorsally and sonic hedgehog ventrally; Ericson et al., 1995; Galceran et al., 2000; Campbell, 2003). The graded signaling of dorsal and ventral morphogens is translated into regional transcription factor codes (Horton et al., 1999; Galceran et al., 2000; Wilson and Rubenstein, 2000; Yun et al., 2001). The next phase in neuronal development, between E10.5 and E17.5, is neurogenesis and early differentiation that produce postmitotic "young" cornu ammonis of the hippocampus (yCA) neurons from HPs in the CA region of the hippocampus (Altman and Bayer, 1990a; Fig. $1 A, B$, developmental stage 2 ). Neurogenesis of yGCs in the developing DG of the hippocampus is delayed, peaking during the first week of postnatal (P) life in rodents (Altman and Bayer, 1990b). Propagation/differentiation of SPs occur between E13.5 and E17.5, producing postmitotic yMSNs in the developing striatum (Wichterle et al., 2001). Final maturation of neurons in both the hippocampus and striatum begins prenatally and continues postnatally (Fig. $1 A, B$, developmental stage 3 ).

\section{Materials and Methods}

Mice. Animal experiments were performed in accordance with the Weill Cornell Medical College Institutional Animal Care and Use Committee guidelines. All mice were group-housed up to five per cage, with a $12 \mathrm{~h}$ light/dark cycle and with lights on at 6:00 A.M. Food and water were available ad libitum. Wild-type C57BL/6 males were purchased from The Jackson Laboratory. Conditional Dnmt3a knock-out males were generated by breeding C57BL/6 mice carrying floxed Dnmt3a alleles (Dnmt3a f/f; Kaneda et al., 2004; provided by Riken BioResource Center) and mice heterozygous for the tamoxifen (Tam)-inducible nestin-cre-ERT2 transgene (cre; Chen et al., 2009; kindly provided by Luis Parada, University of Texas Southwestern Medical Center, Dallas, TX). Dnmt $3 a^{f / f}$ females were crossed with $D n m t 3 a^{f / f}$ cre males to obtain Dnmt $3 a^{f / f}$ and $D n m t 3 a^{f / f}$ cre littermates. To induce Cre-mediated Dnmt $3 a$ excision, pregnant females were injected with $6.7 \mu \mathrm{g} / \mathrm{kg}$ Tam at E13.5, as described previously (Chen et al., 2009). Because gestational tamoxifen injection interferes with females' maternal care behavior, newborn pups were cross-fostered to WT mothers.

Tissue collection for DNA isolation. E14 ESCs were cultured as described previously (Oh et al., 2013). Hippocampal progenitors were microdissected from the epithelium of the ventricular germinal layer, whereas striatal neuronal progenitors were isolated from the LGE of E10.5 embryos. Young CA neurons and young MSNs were dissected from the early hippocampus and striatum, respectively, from E17.5 embryos. CA1 and CA3 pyramidal neurons and GCs were microdissected and isolated from frozen dorsal and ventral hippocampal $200 \mu \mathrm{m} \mathrm{sec}-$ tions of 8- to 10-week-old male mice. MSNs were isolated as described previously (Jiang et al., 2008; Matevossian and Akbarian, 2008). Briefly, dorsal and ventral striatum were dissected. Nuclei were isolated and incubated with anti-NeuN antibody (Millipore, MAB377X) followed by FACS at the Weill Cornell Flow Cytometry Core Facility.

Bisulfite sequencing. DNA was isolated from collected tissue using the DNeasy Blood and Tissue Kit (Qiagen). Single-end 50 bp enhanced reduced representational bisulfite sequencing was performed as described previously (Akalin et al., 2012a), using Illumina HiSeq2000 according to the manufacturer's instructions. An in-house pipeline was used for methylation calling and alignment to the $\mathrm{mm} 9$ reference genome (Akalin et al., 2012b). Differential methylation and statistical analysis were performed using the MethylKit package in R (Akalin et al., 2012b) at default setting. Differentially methylated sites were defined as sites where the sliding linear model (SLIM)-corrected $p$-values were $\leq 0.01$ and the difference in methylation between two samples was $\geq 20 \%$. Differentially methylated regions (DMRs) were defined as regions containing at least four differentially methylated sites with distance no greater than $1 \mathrm{~kb}$. Genomic and CpG island (CGI) annotations were based on Ensmbl data downloaded from the University of California, Santa Cruz (UCSC) genome browser. Promoters were defined as regions $\pm 2 \mathrm{~kb}$ from the transcription start site (TSS), whereas exons and introns were defined by reference. The percentage of total differentially methylated sites in a defined genomic feature was divided by the percentage expected to overlap each genomic feature by chance, based on the percentage of genomic space occupied by that feature, to determine the fold change from expected values. Additional methylation datasets were downloaded from the UCSC genome browser DNA methylation track hub (Seisenberger et al., 2012; Smith et al., 2012; Song et al., 2013). All graphs and statistical analysis were performed using R (www.r-project.org), Bioconductor (www.bioconductor.org), and ggplot2 (www.ggplot2.org) for visualization, unless stated otherwise. Data have been deposited in the Gene Expression Omnibus (GEO) repository: GSE72700.

RNA-Seq. Adult mice were perfused with 30\% RNAlater (Ambion) in saline. Embryonic and adult hippocampal samples were isolated as for DNA. Dorsal striata were microdissected from frozen $200 \mu \mathrm{m}$ adult brain sections. Total RNA was isolated using the RNeasy Mini Kit (Qiagen). Single-end 50 bp RNA sequencing was performed on an Illumina HiSeq 2000 for HP, SP, yCA, and yMSN samples. RNA from dorsal striatum was sequenced using $75 \mathrm{bp}$ pair-end sequencing. Adult GC and CA1 pyramidal neuron RNA data were from our previous report (GSE52069ECS; Liu et al., 2014). ESC RNA data were downloaded from GSE20851. All reads were aligned to the $\mathrm{mm} 9$ reference genome using TopHat software version 2.0.11 (Kim et al., 2013). Default parameters were used with the addition of "-no-novel-juncs" to align exclusively to known genes and isoforms. Gene counts were performed using the HT-seq program (An- 
A

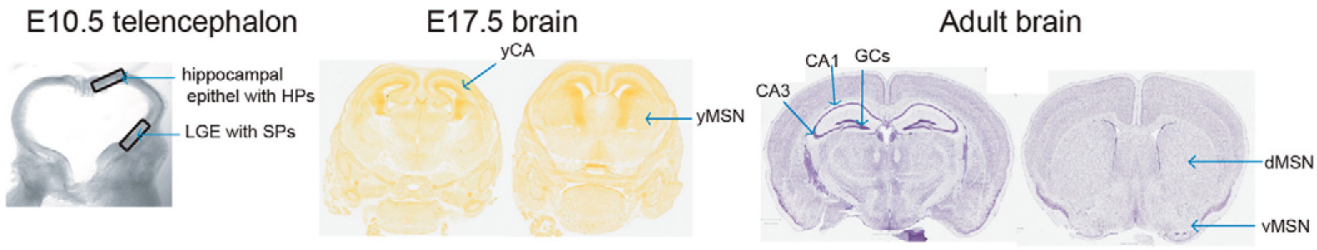

B

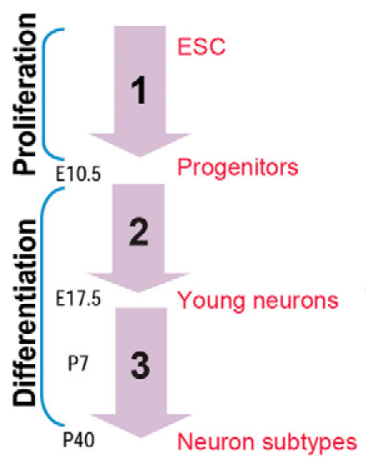<smiles>CO[Te]C</smiles><smiles>P#P</smiles>

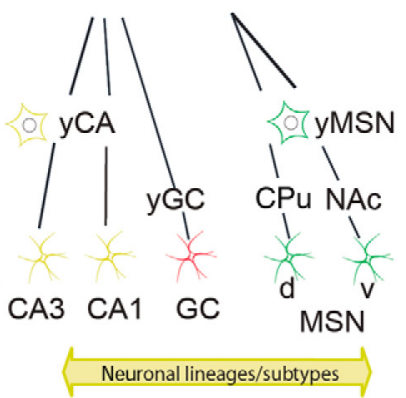

C

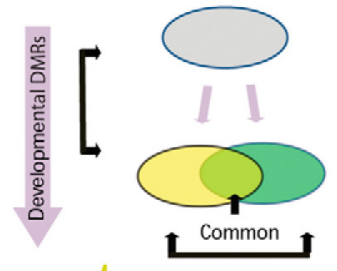

Neuronal lineage/subtype DMRs

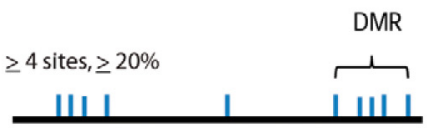

DMR 300-350bp

D

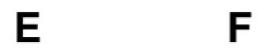

Hypomethylated sites $\left(10^{3}\right) \quad$ Hypermethylated $\left(10^{3}\right)$
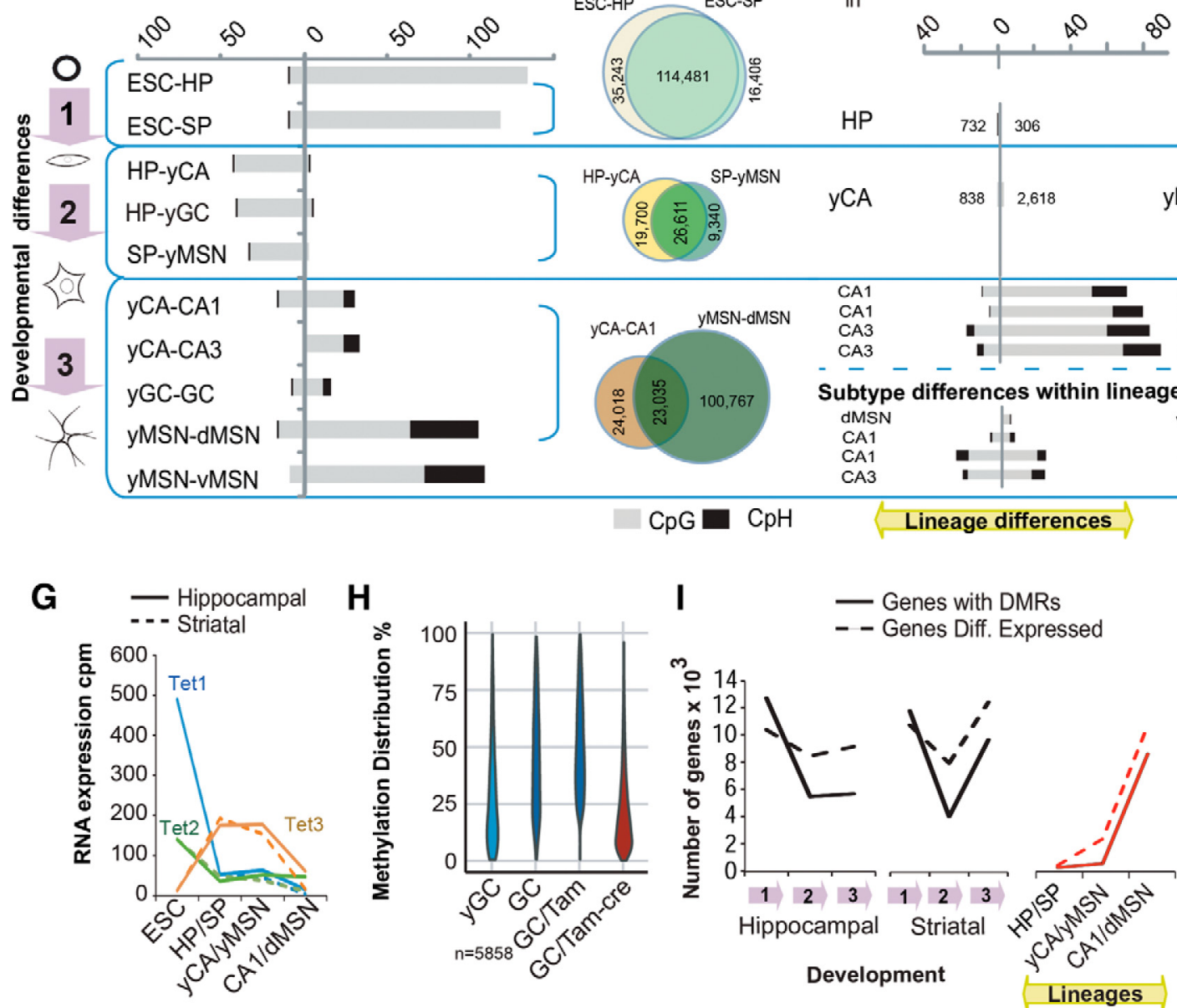

Figure 1. Dynamics of neuronal DNA methylation during hippocampal and striatal development. $\boldsymbol{A}$, Isolation of populations of neuronal progenitors and neurons. Left, Photograph of E10.5 telencephalon illustrating the position of the ammonic/dentate epithelium and LGE, which were the source of HPs and SPs, respectively. Middle, E17.5 telencephalon, showing the developing hippocampus and striatum, and which served as the source of yCAs and yMSNs. Right, Adult mouse brain sections illustrating the distinct cell body layers of CA1 and CA3 (Figure legend continues.) 
ders et al., 2015) with the parameter "intersection-strict." Values for fold change in gene expression were calculated using the EdgeR (Robinson et al., 2010) package in R, using tagwise dispersion and default parameters. Differentially expressed genes were defined as genes containing a Benjamini-Hochberg-corrected $p$-value $<0.05$.

Transfection and luciferase reporter assay. Intronic DMRs as well as a control Drosophila sequence were amplified by PCR [Droso208 forward (F) sequence: CATAGTACTAGGATCCACGCCTAAAGCAACTCCAC, Droso208 Reverse (R): GTTACATGTTGGATCCAGGGATGGGCGTTG GAGA; Crhr1 F: CATAGTACTAGGATCCCGGTCCTCGAATTCCTCA, Crhr1 R: GTTACATGTTGGATCCCGGTGACTCAGCTGTCCT; Park2 F: CATAGTACTAGGATCCTCAAGTGGTGGAACTGGG, Park2 R: GTTAC ATGTTGGATCCCAAGGATCCCGGCTACAG; Htrla F: CATAGTAC TAGGATCCCGGCCTAGCCTCAACTCA, Htrla R: GTTACATGTTG GATCCCGGTACTTGGGACAAGAG; Grid2 F: CATAGTACTAGGAT CCCACTGTCTCAATGCAAATCC, Grid2 R: GTTACATGTTGGAT CCATTTCTTGGGACAACCCAG; Nrxn3 F: CATAGTACTAGGATCC ACGGTGCCCCCGGGGGTA, Nrxn3 R: GTTACATGTTGGATCCCTC CCCATCCCGGCAAGC; Grial F: CATAGTACTAGGATCCTGGAGT CCTCCGGGCTGA, Grial R: GTTACATGTTGGATCCAGAAAAG AGCCGGCAGCT] and were cloned into basic (with no promoter or enhancer activity) and promoter (containing minimal EF1 promoter with no enhancer activity) pCpG-free backbone vectors (InvivoGen). Plasmids were constructed using the In-Fusion Cloning Kit (Clontech Laboratories). $\mathrm{N} 2 \mathrm{~A}$ cells were cultured in medium containing $88 \%$ DMEM $+10 \mathrm{~mm}$ HEPES, $1 \%$ penicillin/streptomycin, $10 \%$ fetal bovine serum, and $1 \%$ L-glutamine in a $5 \% \mathrm{CO}_{2} 37^{\circ} \mathrm{C}$ incubator. Plasmids were transfected into N2A cell cultures using Lipofectamine Transfection Reagent (Life Technologies) in triplicates. Briefly, 200,000 cells were seeded per well in 12-well plates in $1 \mathrm{ml}$ culture medium. Twenty-four hours later, $1 \mu \mathrm{g}$ of plasmid DNA was diluted in $85 \mu$ l of Opti-MEM (Life Technologies) in tubes. After $5 \mathrm{~min}$ of incubation, $6 \mu \mathrm{l}$ of Lipofectamine Transfection Reagent was added, followed by $20 \mathrm{~min}$ of incubation. A total of $85 \mu \mathrm{l}$ of this solution was added to each well of N2A cells. The following day, medium was aspirated and replaced with $400 \mu \mathrm{l}$ of culture medium. Forty-eight hours after transfection, $20 \mu \mathrm{l}$ aliquots of medium were sampled into 96-well plates. A total of $100 \mu \mathrm{l}$ of Quanti-Luc luciferase substrate (InvivoGen) was added to each well, and plates were read immediately for luciferase activity. Luciferase activity data are shown as mean \pm SEM. Outlier data were excluded based on \pm 2 S.D. from the mean.

Statistical analysis. One-way or repeated-measures ANOVAs or $t$ tests were used. Least significant difference (LSD) post hoc analysis was used to assess statistical significance.

\section{$\leftarrow$}

(Figure legend continued.) neurons and GCS, as well as the dorsal MSNs (dMSN) in the dorsal striatum and ventral MSNs (vMSN) in the ventral striatum or nucleus accumbens (NAc). E17.5 and adult brain images are from http://developingmouse.brain-map.org. B, Schematic diagram of the developmental "tree" of hippocampal and striatal lineages in the telencephalon. DNA methylation changes were studied during three consecutive developmental periods that span the production of progenitors (stage 1), neurogenesis and early differentiation to "young" (y) neurons (stage 2), and maturation to subtype-specific neurons (stage 3). d, Dorsal; $v$, ventral; $\mathrm{CPu}$, caudate-putamen; NAC, nucleus accumbens. C, Methylation differences are analyzed vertically, through development within lineages and horizontally, across lineages and subtypes. DMRs are defined as regions with 4 or more clustered differentially methylated sites. D, Hypermethylation and hypomethylation at $\mathrm{CpGs}$ (gray bars) and ( $\mathrm{pHs}$ (black bars) during the three developmental periods, as shown in $\boldsymbol{A}$. $\boldsymbol{E}$, Extensive overlap between lineages during proliferation and early differentiation but diversification in differentially methylated sites during maturation. $\boldsymbol{F}$, Lineage differences in $\mathrm{CpG}$ and $\mathrm{CpH}$ methylation across development and subtypespecific methylation differences in mature neurons. $\boldsymbol{G}$, Developmental time course of Tet mRNA levels. cpm, Count per million mapped reads. $\boldsymbol{H}$, Inactivation of Dnmt3a in developing GCs by Tam-induced Cre prevents gain in methylation during GC maturation. Tam, tamoxifen; cre, nestin-cre-ERT2. I, Developmental and lineage-specific methylation and gene expression changes/differences have parallel trajectories.

\section{Results}

\section{Alternating waves of gain and loss of methylation in the telencephalon during neuronal development}

We determined DNA methylation patterns in two distinct neuronal lineages across development, starting with pluripotent stem cells that produce dorsal and ventral telencephalic neural progenitors which, in turn, differentiate to various hippocampal and striatal neurons (Fig. 1 $A, B$ ). In principle, methylation changes can be measured in two "dimensions" during neuronal development; "vertically" through discrete steps of development in individual lineages (developmental specific) and "horizontally" across lineages/subtypes at each developmental stage (Fig. 1C). Differences in developmental methylation between lineages create lineage/subtype specificity. ESCs, which can be differentiated toward the neuronal fate (Kamiya et al., 2011), were used as reference. Mouse ESCs, presumably because of their serial propagation in culture, have a DNA methylation pattern similar to that of E6.5 epiblasts (Mohn et al., 2008; Smith et al., 2012), the last of pluripotent undifferentiated cells in the embryo (Papaioannou et al., 1975). Indeed, we found a high concordance between methylation in our ESCs and that in E6.5 epiblasts (Smith et al., 2012) at CpG sites ( $t=586.375, \mathrm{df}=79,829, p<2.2 e^{-16}$; $r=0.9008746)$. Because of its higher coverage, our ESC dataset was used in all studies. Progenitors and young neurons were isolated by microdissection from cryosectioned slices of E10.5 and E17.5 brains, respectively. Neuronal cell bodies of adult glutamatergic CA pyramidal neurons and GCs were isolated from cryoslices from the granule cell layer of DG and the stratum pyramidale of the hippocampus (Fig. $1 A$ ). These regions have a very low number of non-glutamatergic neurons (i.e., interneurons) and non-neuronal cells (i.e., GFAP-positive glia). Although the striatum has a higher number of non-neuronal cells, $\sim 95 \%$ of neurons are MSNs within the striatum (Tepper and Bolam, 2004). Therefore, MSN-enriched neuronal populations were obtained by FACS following staining for the neuronal marker NeuN of adult brains, as described previously (Jiang et al., 2008). Moreover, the threshold for differential methylation was set to $20 \%$ (in addition to a statistical difference at SLIM-corrected $p<0.01$ ) to further assure that changes in methylation are related to the most abundant cell types (i.e., CA1, CA3 neurons etc.) in the samples. The 10 isolated populations of cells, ranging from pluripotent ESCs through neuronal progenitors to young and mature postmitotic neurons, were subjected to bisulfite sequencing. Methylation at $\sim 1.5$ million CpGs and $\sim 7$ million non-CpGs was measured genome-wide at relatively $\mathrm{CpG}$-rich and gene-rich regions that included $\sim 2 / 3$ of the promoters, $3 / 4$ of the CpG islands, and a substantial fraction of exons (Gu et al., 2011; Akalin et al., 2012a). To test reproducibility, the GC genomes of six mice were individually bisulfite sequenced. This analysis revealed a high concordance of methylation status between the replicates (Pearson's correlation coefficient $0.98-0.99$ ).

When plotted along chromosomes, differentially methylated sites were either sparsely distributed or clustered in groups of $\geq 4$ in areas of a few hundred base pairs (Fig. 1C). Although methylation changes at single $\mathrm{CpG}$ sites can result in significant functional changes, we focused on regions with clustered differentially methylated sites as they more reliably predict true differential methylation, given the nature of multiple testing (Bock, 2012). Furthermore, because we aimed to identify DMRs that are defined by the actual location of clustered differentially methylated sites with methylation changes in both directions, rather than an arbitrary window size with a change in average methylation, we chose to specify DMRs as re- 
gions containing a minimum of 4 differentially methylated sites, either at $\mathrm{CpG}$ or non-CpG $(\mathrm{CpH})$ dinucleotides. We selected the distance between two differentially methylated sites to be no greater than $1 \mathrm{~kb}$, but the actual average distance between clustered sites was only $40-60$ bps. The size of DMRs ranged between 294 and 334 bps and contained 5.8-7.3 differentially methylated sites across developmental stages and between neuronal subtypes (Fig. $1 C$ ). DMRs were not enriched in $\mathrm{CpG}$ islands as they typically had lower CpG content and resided distal to transcriptional start sites (see below). The reproducibility of identifying DMRs was demonstrated by the high concordance between clustered differentially methylated sites during the transition of young neurons to mature GCs in two sets of neurons (Pearson's correlation coefficient $0.801, t=94.6022$, $\mathrm{df}=$ 4968, $p$-value $\left.<2.2 e^{-16}\right)$.

We found large-scale changes in methylation, with alternating hyper-, hypo-, and, again, hypermethylation, through the three distinct periods of neuronal development (Fig. 1D). During the establishment of progenitors (up to E10.5), approximately one tenth of the 1.48 and 1.36 million profiled CpG sites were differentially methylated within clusters (10.4\% and $9.6 \%$ of CpGs in HPs and SPs, respectively). Most of these changes involved hypermethylation $(93.4 \%$ and $92.6 \%$ in HPs and SPs, respectively, Fig. $1 D)$. Methylation at $\mathrm{CpHs}$ was minimal $(<0.1 \%)$. Since the genome of ESCs, but not of fibroblasts and most somatic cells, is methylated at non-CpG sites (Ramsahoye et al., 2000; Lister et al., 2009; Ziller et al., 2011), loss of $\mathrm{CpH}$ methylation during early neuronal development was also assessed. In line with these studies, we found that $2.5 \%$ of all methylated cytosines were at $\mathrm{CpHs}$ in ESCs and that $\mathrm{CpH}$ methylation was reduced by $94 \%$ during the transition from ESC to progenitors. Overall, the $>100,000$ differentially methylated sites (almost exclusively CpGs) clustered into 20,588 and 18,296 DMRs, corresponding to 12,872 and 11,909 genes, for the hippocampal and striatal lineages (Fig. 1I, stage 1$)$.

During neurogenesis/early differentiation, as progenitors gave rise to young postmitotic neurons, there was a substantial loss of methylation and/or active demethylation, both in the dorsal and ventral telencephalon (Fig. 1D). Again, changes were almost exclusively at CpG sites. Overall, the $\sim 25,000-45,000$ differentially methylated sites clustered into 7625 and 6067 DMRs, corresponding to 5569 and 4107 genes, for the hippocampal and striatal lineages (Fig. 1I, stage 2).

Finally, during the third period, as young neurons matured to field-specific CA1/CA3 pyramidal neurons, GCs and MSNs, methylation again increased (Fig. $1 D$ ). Substantially more methylation occurred in the striatal than in the hippocampal lineage. In contrast to the two previous developmental periods, methylation in this period involved not only CpGs but a substantial number of $\mathrm{CpH}$ sites $(23.2 \%$ and $33.2 \%$ of all methylated cytosines in CA1 neurons and MSNs, respectively), in particular in CpA context. This finding is consistent with previous reports describing significant $\mathrm{CpH}$ methylation, predominantly at $\mathrm{CpAs}$, in neurons (Ramsahoye et al., 2000; Lister et al., 2009; Ziller et al., 2011; Harris et al., 2010; Xie et al., 2012). Overall, the $~ 50,000-$ 100,000 differentially methylated sites clustered into 8028 and 18,717 DMRs, corresponding to 5770 and 9787 genes, during the yCA to CA1 and yMSN to dMSN transitions, respectively (Fig. 1I, stage 3 ). In conclusion, the neuronal genome undergoes alternating, largely unidirectional changes, at consecutive stages of neuronal development. Whereas a previous in vivo developmental study indicated simultaneous methylation and demethylation during neuronal differentiation (Lister et al., 2013), our data, presumably because of their higher temporal resolution, show a distinct phase with loss of methylation between two phases of gain in methylation.

\section{Regulation of loss and gain of methylation during neuronal differentiation}

The mostly uniform hypomethylation during the progenitor to young neuron transition (stage 2, Fig. 1D) may be explained by passive loss of methylation because of the proliferation of neuronal progenitors, in the apparent absence of significant DNA methylation. Nevertheless, a number of active demethylation mechanisms exist and therefore we surveyed the expression of all known enzymes with confirmed or putative DNA demethylase activity by RNA-Seq. We found a 5- and 7-fold increase, respectively, in apobec 2 expression in yCA neurons and yMSNs, relative to that in HPs and SPs. Although the AID/APOBEC family has been implicated in demethylation (Fritz and Papavasiliou, 2010), differentially methylated sites that were hypomethylated in P5 WT yGCs were similarly hypomethylated in apobec $2^{-1-}$ yGCs (kindly provided by Nina Papavasiliou, The Rockefeller University), indicating no consequence of the absence of the protein on methylation during neuronal differentiation (data not shown). Alternatively, loss of methylation could be due to the 10-11 translocation (TET) family of enzymes via hydroxylation, followed by reversion to unmethylated cytosines through iterative oxidation and thymine DNA glycosylase-mediated base excision repair (Kohli and Zhang, 2013). Expression of Tet1 and Tet 2 were high in ESCs but declined from the progenitor stage and remained low through neurogenesis and maturation. In contrast, expression of Tet 3 was initially low in ESCs, higher in progenitors and young neurons, and again low in mature neurons (Fig. 1G). Since this time course is consistent with loss of methylation between the progenitor and young neuron stages, Tet3 may contribute to demethylation during stage 2 of development.

In the next developmental stage, characterized by the transition of young to mature neurons in the hippocampus and striatum (stage 3, Fig. 1D), there was an overall gain in methylation at both $\mathrm{CpG}$ and non-CpG sites. The de novo methyltransferase DNMT3a is essential for $\mathrm{CpH}$ methylation (Ramsahoye et al., 2000; Ziller et al., 2011; Arand et al., 2012). Therefore, we conditionally inactivated Dnmt3a by tamoxifen-inducible nestincreERT2, from E13.5 in the hippocampus (75-85\% knockdown efficiency), before the beginning of the young to adult GC transition at E17.5. This prevented the developmental gain in methylation in GCs (Fig. $1 H$ ), implicating DNMT3a in the gain of methylation during GC maturation.

\section{Lineage-specific DNA methylation and transcriptional differences are minimal during neuronal proliferation and early neuronal differentiation, but substantial during neuronal maturation}

Although a large number of sites were differentially methylated during the ESC to progenitor transition in the two lineages $(>100,000$, Fig. 1D), most of them (76\% and $88 \%$ for ESC-HP and ESC-SP, respectively) mapped to the same $\mathrm{CpG}$ sites, with the same direction of change (Fig. 1E). This high concordance in developmental methylation between the lineages was reflected in the low number $(\sim 1000)$ of differentially methylated sites and $<500$ DMR genes between HPs and SPs (Fig. 1F,I). Similarly, the large number of developmental transcriptional changes $(>10,000$; RNA-Seq, FDR $<0.05$ ) during the transition from ESCs to progenitors, were accompanied with a relatively small number of transcriptional differences $(<1000)$ between HP and SP (Fig. 1I). These data show that initially, 

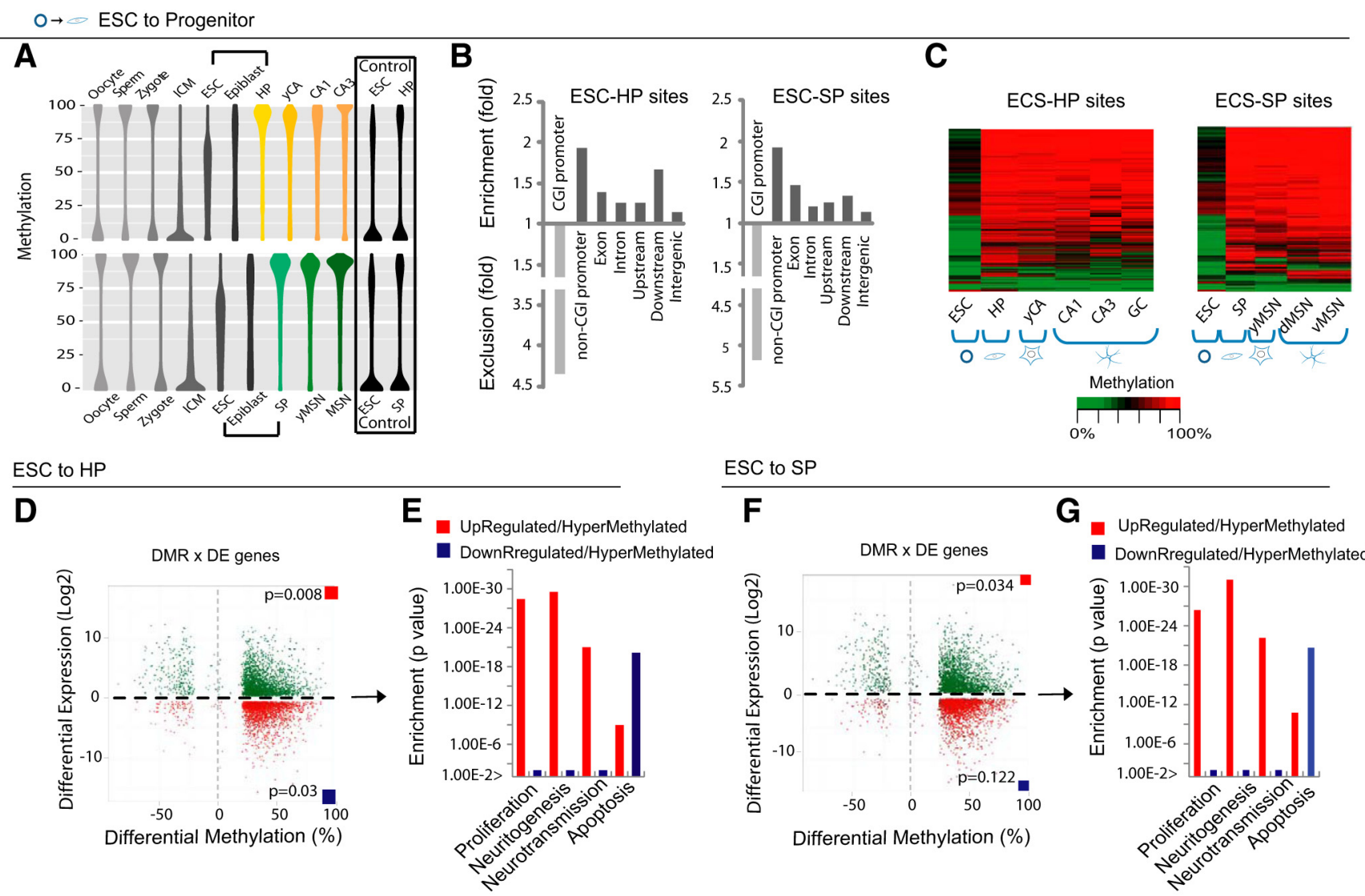

ESC to SP

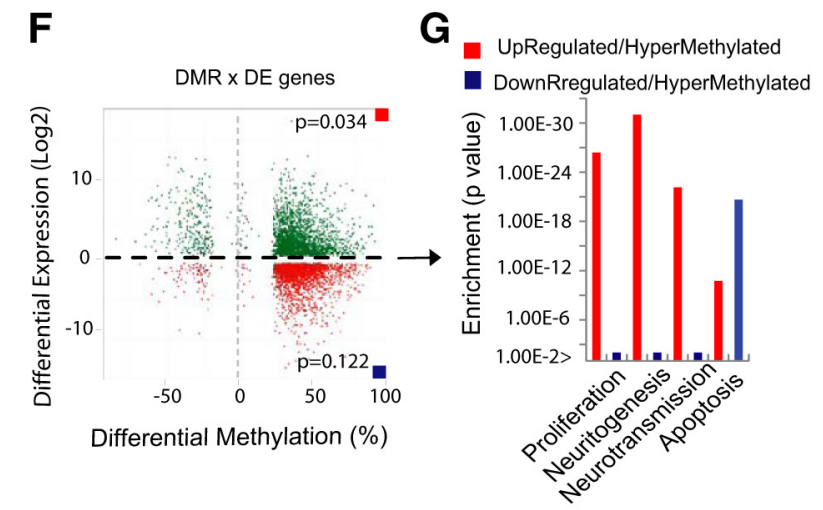

Figure 2. Characteristics of DNA methylation during progenitor proliferation. $A$, Distribution of methylation levels at proliferation-specific differentially methylated sites across development, compared with the methylation of all CpG sites (Control) in ESC and HP/SP. Sites with intermediate methylation in ESCs (and in epiblasts) are preferentially targeted, while genomic CpGs overall show a bimodal distribution in ESCs and progenitors (Controls). The sites with intermediate methylation in ESC acquire high methylation level in HPs and SPs and maintain it through neuronal differentiation. In oocytes and sperms, as well as in zygotes, (pGs at proliferation-specific sites have the typical bimodal methylation distribution and are demethylated during reprogramming in the inner cell mass (ICM). B, Enrichment and depletion of proliferation-related sites in genomic features (fold difference, compared with the representation of all profiled (pGs). $\boldsymbol{C}$, Heat map representation of methylation levels highlighting the permanence of most HP and SP differentially methylated sites across development. $\boldsymbol{D}, \boldsymbol{F}$, Genes with differential methylation (mean methylation of differentially methylated sites within a gene) and expression. Hypermethylation during HP and SP proliferation is associated with both gene activation and repression. Numbers in the individual quadrants represent Parson expression vs methylation correlation $p$ values. $\mathbf{E}, \mathbf{G}$, Hypermethylated/upregulated (red) and hypermethylated/downregulated (blue) genes belong to different functional categories in both the dorsal and ventral telencephalon.

the methylation and transcriptional programs in the hippocampal and striatal lineages are highly similar (Fig. 1I).

Despite the large-scale methylation changes during the progenitor to young neuron transition $(\sim 25,000-45,000$; Fig. $1 D$, stage 2 ), most sites were still similarly modified in the two lineages (Fig. 1E). Consequently, the number of lineage-specific differentially methylated sites and corresponding DMR genes was still relatively low (Fig. $1 F, I$ ). Transcription showed a similar trend: large developmental and limited lineage-specific changes (Fig. 1I). These data indicate that during the progenitor to young neuron transition, the methylation and transcriptional programs are still similar in the two lineages, although transcription becomes somewhat more diverse between the lineages (Fig. 1I).

In contrast to the previous developmental stages, neural maturation was characterized by 3-4 times more methylated sites in the striatum than in the hippocampus (Fig. 1D). This resulted in less overlap between the lineages (Fig. 1E) and, consecutively, larger diversity in methylation across lineages (Fig. $1 F, I$ ). Transcriptional changes, both developmental and lineage specific, were on par with these changes (Fig. 1I). Methylation differences were observed not only between hippocampal and striatal mature neurons, but between neuronal subtypes within brain regions as well, particularly in the hippocampus (Fig. $1 F$ ). This suggests that the DNA methylation program progresses in a field-specific manner in the hippocampus, while the striatal pattern remains relatively uniform in the dorsal and ventral compartments. This is consistent with the successive birth and migration of CA3, CA1, and finally GC neurons in the hippocampus. In contrast, the dorsal and ventral MSNs, destined to the caudate-putamen and nucleus accumbens, are produced and migrate simultaneously (Grove and Tole, 1999; Wichterle et al., 2001). Together, our results show that the developmental methylation program is remarkably similar initially in the hippocampus and striatum, with significant divergence only occurring during neuronal maturation. The transcriptional program shows a parallel trajectory (Fig. 1I).

\section{Widespread DNA methylation at partially methylated sites during neuronal progenitor proliferation}

Gain in methylation during the establishment of the progenitor pool was targeted to sites with an intermediate level of methylation (25-75\%) in ESCs (and in E6.5 epiblasts) and methylation at these sites shifted to a higher level in both the dorsal and ventral progenitors (Fig. 2A). Intermediately methylated sites represent a fraction of all CpGs in ESCs and epiblasts, since methylation is bimodal, with most $\mathrm{CpG}$ sites either methylated ( $>75 \%$ ) or un- 
methylated ( $<25 \%$; Fig. 2A, Controls). In inbred mice, like those used in our experiments, intermediate methylation reflects cellto-cell variability (except at imprinted genes; Gutierrez-Arcelus et al., 2013). Indeed, differentially methylated sites on the $\mathrm{X}$-chromosome were also intermediately methylated in male ESCs. Intermediate/variable methylation in ESCs and E6.5 epiblasts may represent epigenetic mosaicism due to ongoing, yet uncompleted reprogramming at these sites, that follows the erasure of methylation marks in the early embryo (Seisenberger et al., 2013; Fig. 2A, ICM).

Surveying the genomic location of differentially methylated sites between ESCs and progenitors, we noticed their exclusion from CpG-rich areas, such as CGI promoters. This is consistent with the known resistance of CGIs to methylation (Mohn et al., 2008; Jones, 2012). Instead, ESC-HP/SP differentially methylated sites were enriched in multiple other genomic features (Fig. 2B). This included a substantial fraction of non-CGI promoters ( 5474 and 4498 in hippocampus and striatum, respectively) which became predominantly methylated ( $87 \%$ and $90 \%$ in HP and SP) relative to ESCs. Although the enrichment was lower, extensive methylation also occurred at exons, introns, and intergenic regions in progenitors. Heat map representation of the methylation data indicated that the gain in methylation during progenitor development was mostly permanent (Fig. 2C). Only $9.6 \%$ and $10.2 \%$ of the ESC-HP, and $7.5 \%$ and $14.3 \%$ of the ESC-SP differentially methylated sites, were modified again during the progenitor to young neuron and young to mature neuron transitions, respectively. Only a small fraction of sites (1.9 and 3.5\%) were modified in all three stages of development in the dorsal and ventral telencephalon.

In accordance with the genome-wide methylation during proliferation, a large number of genes were differentially methylated (Fig. $1 I$ ). Approximately $60 \%$ of differentially methylated genes were also differentially expressed (DMR $\times$ DE genes) and could be divided into four categories according to the direction of their methylation and expression change (Fig. $2 D, F$ ). The majority of $\mathrm{DMR} \times \mathrm{DE}$ genes were hypermethylated, consistent with the overall gain in methylation during this period (Fig. 1D), but were associated with both gene activation and repression. This indicated no overall correlation between methylation and gene expression. However, within the hypermethylated and upregulated genes there was an inverse relationship between methylation and expression in both the developing hippocampus and striatum. Moreover, gene ontology analysis by ingenuity pathway analysis (IPA) showed that the upregulated/hypermethylated and downregulated/hypermethylated groups of genes were enriched in different functional categories (Fig. $2 E, G$ ). Upregulated genes were enriched in the cellular processes of proliferation, neuritogenesis, and even neurotransmission. This suggests that aside from stage-specific changes, epigenetic and transcriptional changes supporting later differentiation processes are also underway. In contrast, downregulated genes were solely enriched in apoptotic function.

\section{Intronic and intergenic methylation during neuronal differentiation}

Developmental methylation changes, predominantly hypomethylation, during the progenitor to young neuron transition (Fig. $1 B$, stage 2) were more prevalent in introns and, to a lesser extent, in intergenic areas than expected by chance, while excluded from promoters and exons (Fig. 3A). The modified sites had a predominantly high methylation level in progenitors, which was drastically shifted to a low methylation level in yCA neurons and yMSNs (Fig. 3B), as well as in yGCs. Although loss of methylation during the progenitor to young neuron transition was mostly permanent in the hippocampus, a significant fraction of SP-yMSN differentially methylated sites were remethylated in adult MSNs (Fig. 3C).

During the transition from young to mature neurons (Fig. 1B, stage 3), intron-specific methylation changes were also more abundant (Fig. 3E); but instead of loss, sites gained methylation, both at $\mathrm{CpG}$ and $\mathrm{CpH}$ sites (Fig. $3 F$ ). Introns were also the preferred targets during GC development.

\section{Intronic DMRs have intrinsic gene-regulatory potential}

The preferred intronic localization of DMRs suggested alternative promoter and/or enhancer function. Therefore, we used luciferase reporter constructs in neuronal N2A cells to determine possible transcriptional activity. We selected four relatively short ( $\sim 200$ bp) intronic DMRs that were hypomethylated in both yCA neurons and yMSNs, relative to HPs and SPs. One of these DMRs exhibited promoter activity [Grial, glutamate receptor (AMPA) 1], when inserted into a promoterless construct, while two enhanced the activity of the EF1 promoter (Grid2, glutamate receptor, ionotropic, delta 2 and Grial, trend only; Fig. 3D). Additionally, two selected intronic DMRs, hypermethylated in CA1 neurons and dMSNs relative to yCA neurons and yMSNs, enhanced the activity of the $\mathrm{EF} 1$ promoter construct (Park2, parkin 2, and Crhr1, corticotrophin receptor 1; Fig. 3G), but had no promoter activity. In contrast, an arbitrary 208-bp-long intergenic Drosophila sequence had neither promoter nor enhancer activity. These data indicate that at least some of the intronic DMRs associated with the transition of progenitors to young neurons, and young to mature neurons, have intrinsic gene activation properties and could thus regulate isoform and/or overall gene expression.

\section{Intersecting DNA methylation and gene expression changes across neuronal differentiation identifies developmental stage-specific functional gene clusters}

The parallel changes in DNA methylation and gene expression through development in both the hippocampal and striatal lineages and across lineages suggested that these mechanisms are linked (Fig. 1I). To gain a better understanding of this relationship, we performed functional analyses with genes that were both differentially methylated at intronic/intergenic regions and differentially expressed.

Consistent with the overall loss of methylation during the progenitor to young neuron transition (Fig. 1D), the majority of corresponding DMR $\times$ DE genes were hypomethylated, but split to upregulated and downregulated groups along the $x$-axis (Fig. $4 A$ ). This indicated that there is no overall correlation between methylation and expression. Next, hypomethylated/upregulated and hypomethylated/downregulated genes were separately analyzed by IPA and enrichment $p$ values were displayed along the $z$-axis (Fig. $4 B$ ). Downregulated genes (many of them transcription factors) were enriched in brain morphogenesis, in agreement with the closure of major morphogenic processes in the brain by the end of neuronal proliferation. Upregulated genes represented functions from neuronal proliferation, through migration, and neuritogenesis, to synaptic transmission in both the hippocampal and striatal lineages.

A similar analysis was repeated with genes that were DMR $\times$ DE during late differentiation/maturation (Fig. 4C,D). Although this period is characterized by significant methylation (Fig. 1D), a fraction of DE $\times$ DMR genes were hypomethylated. Although we 
A B

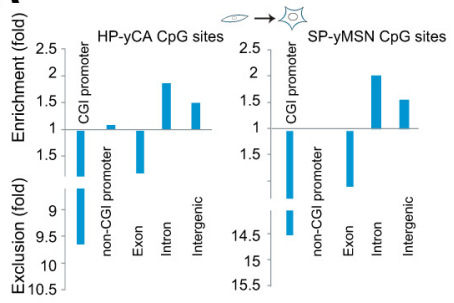

B $C$
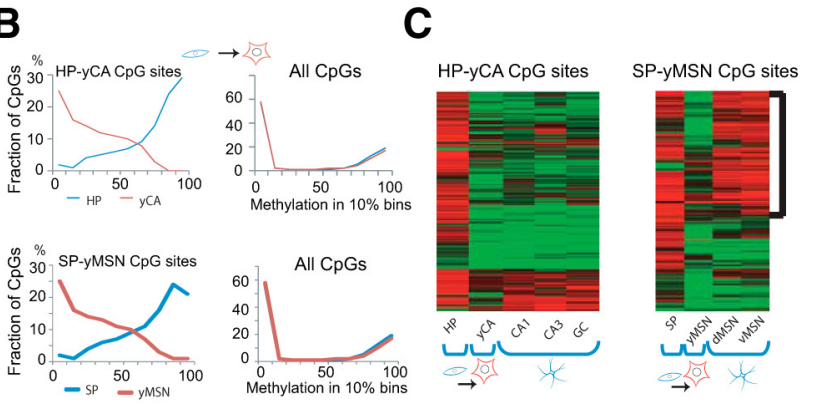

E

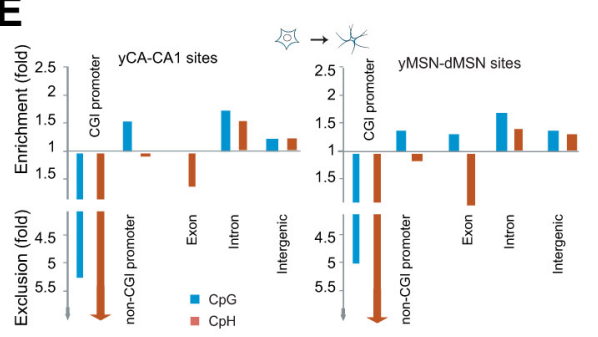

$\mathbf{F}$

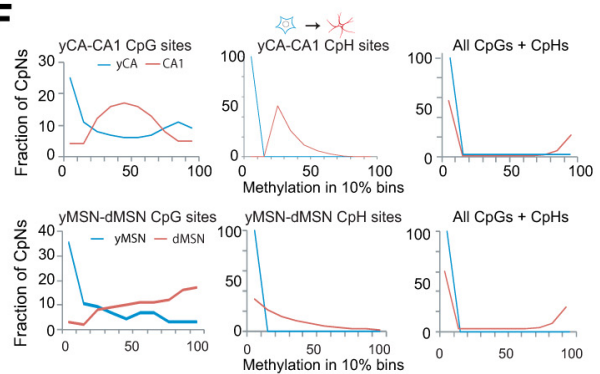

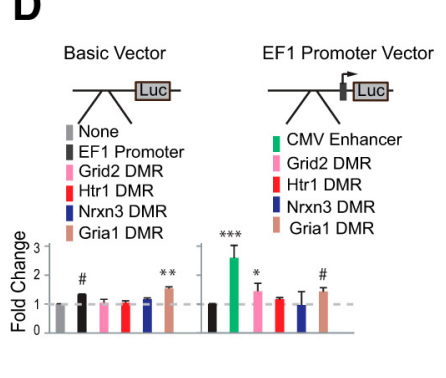

D

G

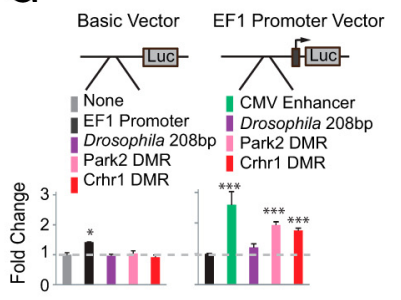

Figure 3. Characteristics of DNA methylation during neuronal differentiation from progenitors to young neurons $(\boldsymbol{A}-\boldsymbol{D})$ and then from young to mature neurons $(\boldsymbol{E}-\boldsymbol{G})$. $\boldsymbol{A}$, Enrichment and depletion of young neuron-specific differentially methylated sites in genomic features (fold difference, compared with the representation of all profiled ( $\boldsymbol{C} G \mathrm{~s}$ ). $\boldsymbol{B}$, Distribution of methylation levels in $10 \%$ bins at HP-yCA and SP-yMSN sites, as well as all profiled CpGs, before (blue) and after (red) the developmental transitions. $\boldsymbol{C}$, Heat map representation of methylation levels at HP-yCA and SP-yMSN CpG sites through development, illustrating that loss of methylation during the progenitor to young neuron transition is mostly permanent, except at a fraction of SP-yMSN sites that are remethylated in adult neurons. $D$, Selected young neuron-specific DMRs have promoter and/or enhancer-like activity in transfected neuronal N2A cells (ANOVA: basic vector, $F_{6.14}=3.272, p=$ 0.032; promoter vector, $F_{6.14}=13.594, p<0.0001$, LSD post hoc, ${ }^{*} p<0.05,{ }^{* *} p<0.01,{ }^{* * *} p<0.005,{ }^{*} p<0.01$ trend). Luciferase expression is expressed in fold change, relative to activities in cells transfected with basic (left) and promoter vector (right). Positive controls are basic vector with EF1 promoter (left) and promoter vector with CMV enhancer (right). $E$, Enrichment and

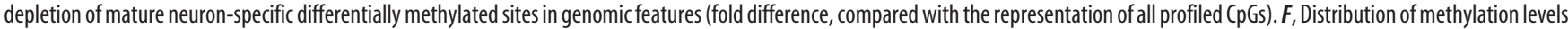
in $10 \%$ bins at yCA-CA and yMSN-MSN sites, as well as at all genomic sites, before (blue) and after (red) the developmental transitions, at CpGs and CpHs. G, Selected mature neuron-specific DMRs have no promoter but significant enhancer-like activity in N2A cells (ANOVA: promoter vector, $F_{4.10}=27.983, p<0.0001$, LSD post hoc, ${ }^{*} p<0.05$, ${ }^{* * *} p<0.005$ ). Luciferase expression is expressed in fold change as indicated in $\boldsymbol{D}$. An intergenic Drosophila control sequence has neither promoter nor enhancer activity. Fold change: mean \pm SE.

still identified genes enriched in neuronal proliferation and migration functions, they were now downregulated, in contrast to their upregulated status during the previous progenitor to young neuron transition. This switch from upregulation to downregulation reflects the cessation of proliferation and migration in both the hippocampal and striatal lineages and was accompanied by the concurrent switch from hypomethylation to hypermethylation, similar to what occurs when proximal promoters and enhancers are inactivated (Stadler et al., 2011). Another interesting trend was that genes associated with maturation processes (apoptosis, neuritogenesis and synaptic transmission) underwent two rounds of hypomethylation/upregulation (Fig. 4D), suggesting a continuing need for these genes and a stepwise gene-regulatory process, presumably to meet different demands during early and late differentiation.

\section{Neuronal subtype-specific DNA methylation and gene expression changes}

Methylation differences between the lineages (hippocampal vs striatal) emerged in substantial numbers, on par with transcriptional changes, during maturation (Fig. 1F,I). Therefore, we analyzed genes DMR $\times$ DE between CA1 neurons/GCs and dMSNs by IPA. This analysis identified well known, as well as unexpected, neuron subtype-specific gene expression and functional differences.

Genes, upregulated in hippocampal relative to striatal neurons $(\mathrm{CA} 1 / \mathrm{GC}>\mathrm{MSN})$, were associated with neuritogenesis and synaptic transmission, suggesting more robust neuronal plasticity in the hippocampus (Fig. $5 \mathrm{~A}$, red and blue columns). Furthermore, $\mathrm{CA} 1 / \mathrm{GC}>\mathrm{MSN}$ genes were enriched in the processes of long-term potentiation (LTP), long-term depression (LTD), and EPSP, distinctive functions in the hippocampus. In contrast, genes upregulated in MSNs relative to CA1/GC (MSN > CA1/GC) were associated with striatal LTD, a process that is different from hippocampal LTD. Striatal LTD is postsynaptically induced, but presynaptically expressed, through retrograde endocannabinoid signaling (Gerdeman et al., 2002), whereas hippocampal LTD is postsynaptic and involves internalization of synaptic AMPA receptors (Malenka and Bear, 2004). The different functional categories of upregulated genes were either hypomethylated or hypermethylated, suggesting that their regulation might be under different mechanisms.

In addition, genes upregulated in hippocampal relative to striatal neurons were enriched in the molecular function of phosphorylation of proteins (Fig. $5 B$, red and blue columns). In contrast, genes upregulated in the striatum were enriched in GABA metabolism and cAMP synthesis, consistent with the neurotransmitter phenotype of MSNs and the Gs/Gi coupling of the striatal dopamine receptors, respectively. Surprisingly, striatal upregulated genes were also enriched in membrane lipid synthesis and steroid biosynthesis. In addition to their role as structural elements, membrane lipids are involved in a multitude of signaling processes and de novo steroid biosynthesis (estrogens, progesterone, and androgens; Do Rego et al., 2009). Our data suggest that lipid signaling and central steroid biosynthesis could be more prominent in the striatum than in the hippocampus.

Finally, we analyzed genes DE $\times$ DMR between CA1 neurons and GCs to assess whether concurrent methylation and expression differences could define neuron subtypes within 

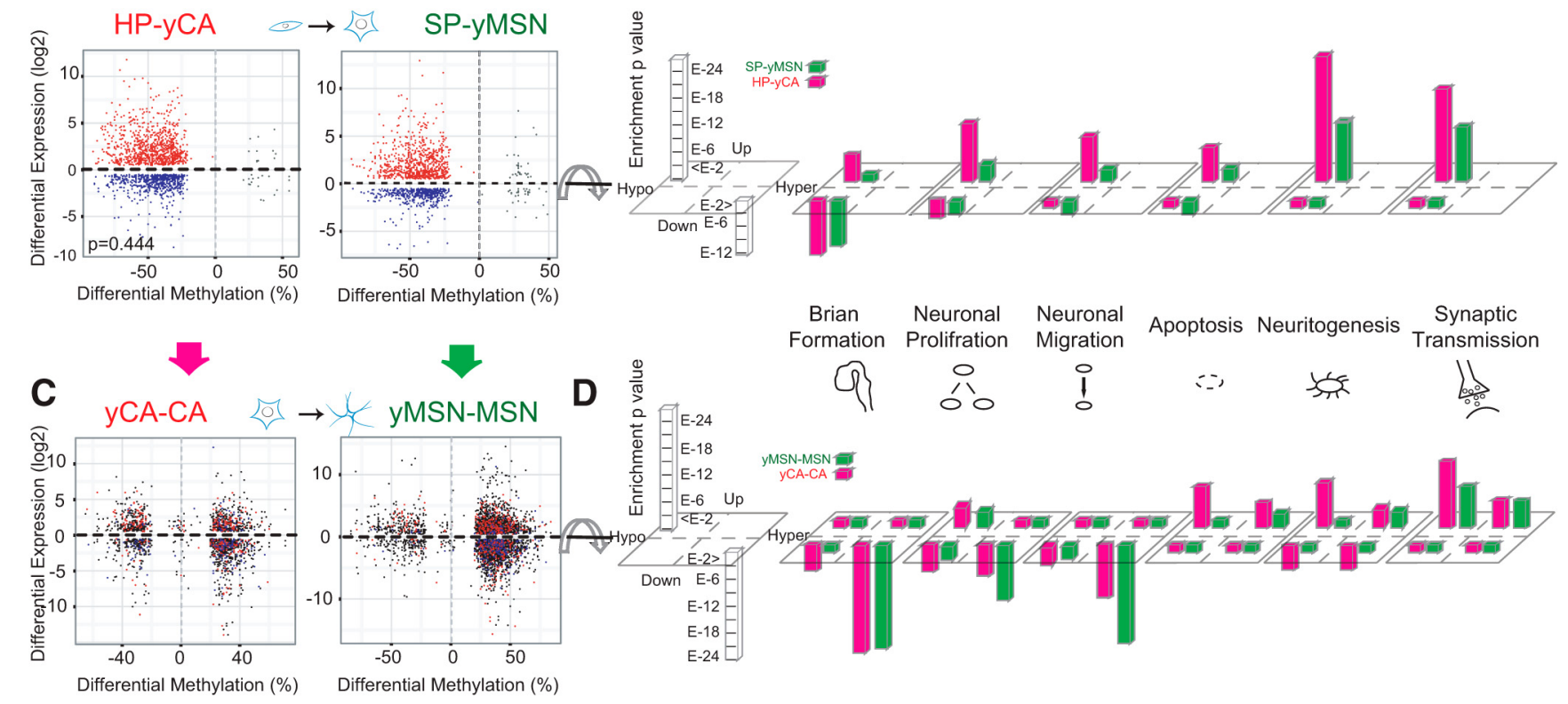

$\begin{array}{cccc}\text { Brian } & \text { Neuronal } & \text { Neuronal } & \text { Apoptosis Neuritogenesis } \\ \text { Formation } & \text { Prolifrationatic } \\ \text { Transmission }\end{array}$

Figure 4. Intersecting DNA methylation and gene expression changes during differentiation identifies developmental stage-specific gene clusters. $A$, Genes differentially methylated during the progenitor to young neuron transition are mostly hypomethylated, but can be either upregulated (hypo/up, red) or downregulated (hypo/down, blue). Very few genes are hypermethylated. $\boldsymbol{B}$, IPA analysis of hypo/up and hypo/down genes. Enrichment $p$ values for these two groups of genes for highly significant functional categories are displayed in quadrants that correspond to their expression/methylation status, along the z-axis. No IPA analysis was performed with hyper/up and hyper/down genes because of their low number. Hypo/down genes are associated with the early steps of brain formation, while hypo/up genes are enriched in a series of neuronal functions that align with the progressive steps of differentiation from migration to synaptic transmission. C, Genes, differentially expressed during the young to mature neuron transitions, are mostly hypermethylated, especially in the striatal lineage, but a substantial number of hypomethylated genes are also present. Genes, previously altered during the progenitor to young neuron transition, are highlighted red (previously hypo/up, $\boldsymbol{A}$ ) and blue (previously hypo/down). $\boldsymbol{D}$, IPA analysis of genes distributed to four groups in $C$, based on their expression and methylation. Only highly significant functions are displayed. Hyper/down genes are enriched in functions associated with early brain development, progenitor proliferation, and migration. Hypo/up genes are associated with later differentiation processes, from neuritogenesis to synaptic transmission.
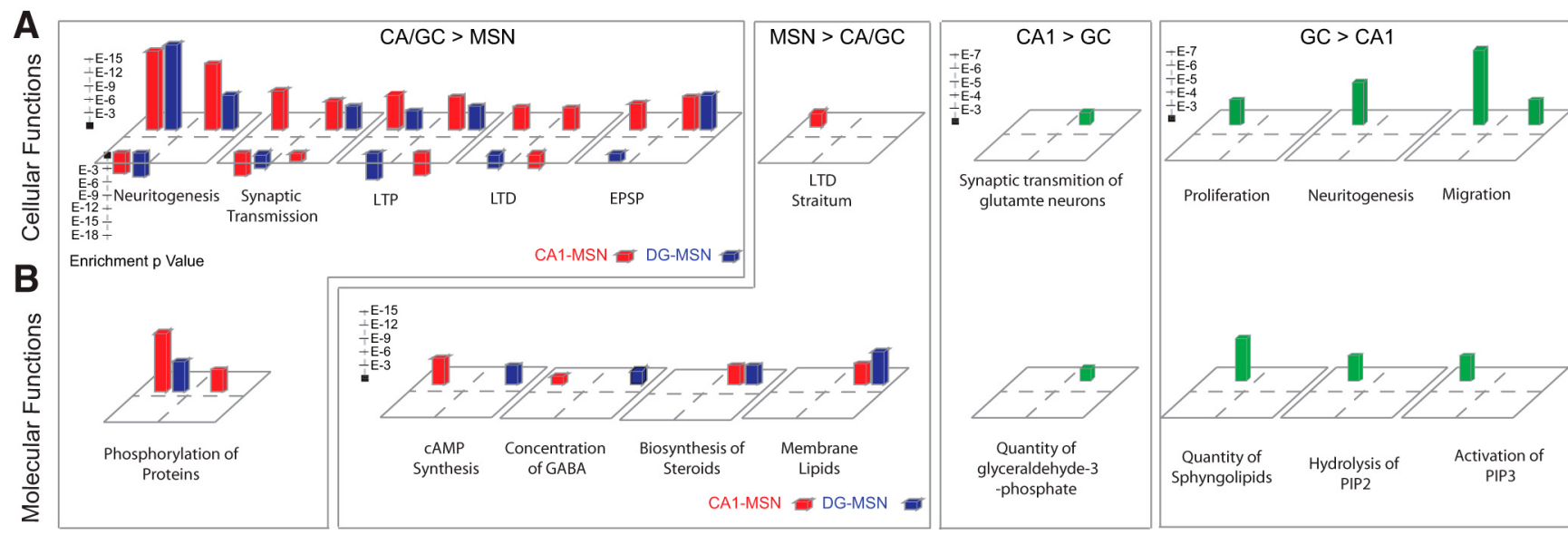

Figure 5. IPA analysis of neuronal subtype-specific DMR $\times$ DE genes between the hippocampus and striatum (CA1 vs dMSN and GC vs dMSN; red and blue columns, respectively), as well as between neurons in the hippocampus (green columns). $\boldsymbol{A}$, Cellular Functions; $\boldsymbol{B}$, Molecular Functions. Higher expression in one cell type is indicated by the symbol " $>$." See Figure $4 B$ for further description.

the hippocampus (Fig. $5 A$, B, green columns). Genes, upregulated in GCs relative to CA1 neurons, were enriched in the biological processes of proliferation, migration, and neuritogenesis. These functions are consistent with the persistent neurogenesis and neuronal replenishment of GCs throughout life, as opposed to the lack of adult neurogenesis in the CA1 layer of the hippocampus. Moreover, genes related to the metabolism of phosphatidylinositol membrane lipids were upregulated in GCs, suggesting a difference in major signaling pathways, such as AKT, between GCs and CA1. Finally, sph- ingolipid metabolism was also a more prominent function in GCs. Sphingolipids are enriched in raft-like microdomains, specialized membrane domains where transmembrane signaling occurs through receptors and associated signaling components (Sonnino et al., 2007). Genes upregulated in CA1 neurons, relative to GCs, were enriched in only a few specific functions with modest scores. No functional differences were found between dMSNs and vMSNs, in agreement with the minimal methylation differences between these two closely related neuronal subtypes (Fig. $1 F$ ). 


\section{Discussion}

Our work describes a set of simple principles that govern in vivo DNA methylation and demethylation during neuronal development. By dividing neurodevelopment to three major stages and applying the principles to each of these stages, we created a matrix that comprehensively describes DNA methylation and demethylation events in two neuronal lineages and five different neuronal subtypes; a total of 10 cell types spanning the entirety of neurodevelopment (Fig. 6).

First, we found alternating large-scale gain and loss of methylation through neuronal development. Although ESCs highly express both Dnmt3a and Dnmt3b, Dnmt3a is the predominant de novo DNA methyltransferase involved in the transition of ESCs to neuronal progenitors ( $\mathrm{Wu}$ et al., 2010). Loss of methylation during early differentiation (E10.5-E17.5) was associated with an increase in Tet3, suggesting its role in active demethylation, although passive methylation may also play a role. Indeed, evidence indicates a fundamental role for Tet 3 , and associated active demethylation, during neuronal differentiation and maturation. Knockdown of TET2 and TET3 expression in E13.5 mouse embryonic cortex leads to abnormal cortical development at E17.5 (Hahn et al., 2013), and Tet3 knock-out ESCs exhibit impaired neurogenesis and increased apoptosis (Li et al., 2015). Methylation during neuronal maturation (from P5 in DG) was likely related to Dnmt3a activity because its conditional knock-out prevented the gain in methylation. These data suggest that specific enzymes of the methylation/demethylation machinery may explain the large-scale changes in methylation dynamics through development.

The second principle underlying developmental methylation is related to the dinucleotide context of the methylated and demethylated cytosines. Initially, gain and loss of methylation are largely limited to CpG sites (other than the loss of ESC-CpHs), while during neuronal maturation, methylation also occurs at a significant number of non-CpG sites in both the hippocampal and striatal lineages. This finding is consistent with previous observations of non-CpG methylation in mouse frontal cortex during fetal to young adult development (Lister et al., 2013) and with the high $\mathrm{mCpH}$ content of the adult brain (Xie et al., 2012; Varley et al., 2013). In summary, these data indicate that $\mathrm{CpH}$ methylation ensues after neurons became postmitotic while undergoing field-specific maturation.

The third principle is that the developmental methylation program is remarkably similar in the hippocampus and striatum, with significant divergence only during neuronal maturation. The transcriptional program shows a similar trajectory, suggesting that methylation and gene expression are mechanistically linked. Interestingly, the DNA methylation

\section{Development}

E10.5 E17.5
Late Early 2

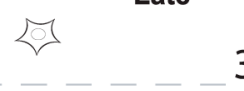

3
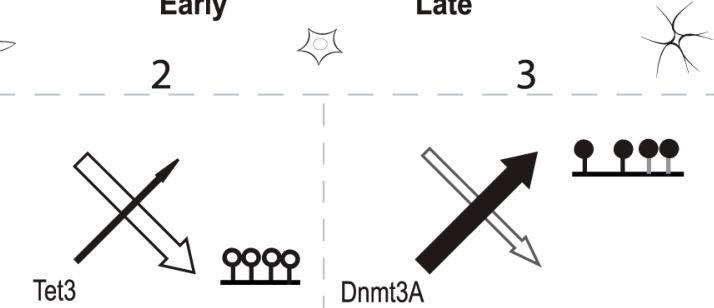

Tet3
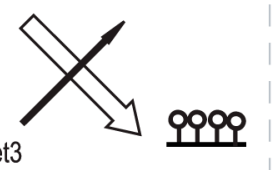

Dnmt3A
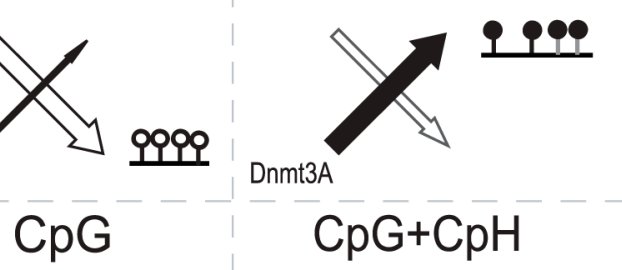

$\mathrm{CpG}+\mathrm{CpH}$

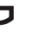
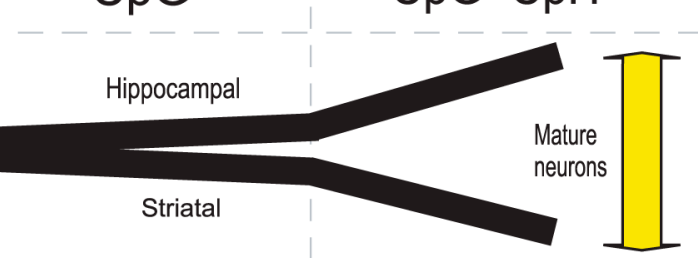

Striatal
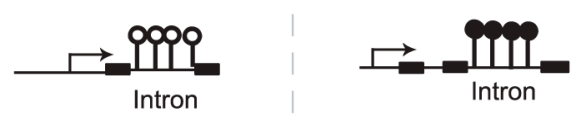

intron

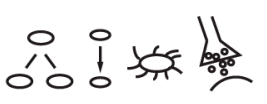

Figure 6. The five general principles governing DNA methylation during lineage and subtype-specific development. These are as follows. I, The program consists of three stages. An initial genome-wide methylation during progenitor proliferation is followed sed by a gain in methylation during maturation to subtype-specific neurons. II, At the first two stages, gain and loss of

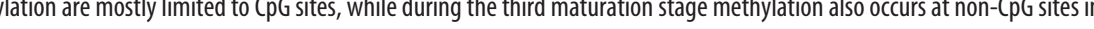
moter and/or enhancer-like activity. V, Differentially methylated genes are enriched in neurodevelopmental functions (from progenitor proliferation, through migration and neuritogenesis, to synaptic transmission); upregulated genes represent current and consecutive stage-specific functions, while downregulated genes represent preceding functions that are no longer required.

program of hematopoietic cells is the exact opposite, dominated by lineage-specific, over developmental stage-specific, methylation changes (Bock et al., 2012).

The fourth principle is that methylation during progenitor proliferation targets most genomic features, except CGI promoters, while later, during young and mature neuron development, loss and gain of methylation occurs preferentially at introns. The initial, large-scale methylation during progenitor proliferation could promote genome integrity since hypomethylated DNA is structurally instable and mutable (Eden et al., 2003; Li et al., 2012). The targeted methylation changes during differentiation could serve regulatory functions, as some of these sites exhibited promoter and/or enhancer-like activity.

Finally, differentially methylated genes were enriched in neurodevelopmental functions; hypomethylated/upregulated genes represented current and consecutive stage-specific functions, while hypermethylated/downregulated genes represented preceding functions that are no longer required. While this suggested a relationship between activity and methylation, we found 
no global methylation-expression correlation encompassing all developmental stages. Therefore, it is possible that correlations exist only within functionally similar genes during specific stages of development.

The overarching theme emerging from our work is that neuronal methylation/demethylation is principally associated with differentiation, with minimal lineage specificity, but later, during neuronal maturation, methylation may significantly contribute to neuron subtype specification. Beyond increasing our understanding of the epigenetic regulation of normal development, this work will be useful in research focused on neurodevelopmental disorders. Neuronal development, like development in general, is highly vulnerable to environmental perturbations. Developmental perturbations can lead to persistent abnormalities, exemplified by autism and schizophrenia stemming from severe maternal gestational infection, or child and adolescent behavioral problems emerging following pre/postpartum maternal stress and maltreatment (Cicchetti and Toth, 2005; Yehuda et al., 2008; Atladóttir et al., 2010). These early life adverse conditions are associated with persistent alterations in the methylome in human and animal models (McGowan et al., 2008; Roth et al., 2009; Oh et al., 2013). Interference with the normal developmental dynamics of DNA methylation or overriding the already established developmental pattern by adverse early life experiences can be fundamental in the etiology of the resulting psychopathology or psychiatric disease-like behaviors in animal models. Our developmental methylation matrix can be cross-referenced with disease-associated methylation changes to specify the possible events and underlying principles that are compromised in disease.

\section{References}

Akalin A, Garrett-Bakelman FE, Kormaksson M, Busuttil J, Zhang L, Khrebtukova I, Milne TA, Huang Y, Biswas D, Hess JL, Allis CD, Roeder RG, Valk PJ, Löwenberg B, Delwel R, Fernandez HF, Paietta E, Tallman MS, Schroth GP, Mason CE, et al. (2012a) Base-pair resolution DNA methylation sequencing reveals profoundly divergent epigenetic landscapes in acute myeloid leukemia. PLoS Genet 8:e1002781. CrossRef Medline

Akalin A, Kormaksson M, Li S, Garrett-Bakelman FE, Figueroa ME, Melnick A, Mason CE (2012b) methylKit: a comprehensive R package for the analysis of genome-wide DNA methylation profiles. Genome Biol 13:R87. CrossRef Medline

Altman J, Bayer SA (1990a) Prolonged sojourn of developing pyramidal cells in the intermediate zone of the hippocampus and their settling in the stratum pyramidale. J Comp Neurol 301:343-364. CrossRef Medline

Altman J, Bayer SA (1990b) Migration and distribution of two populations of hippocampal granule cell precursors during the perinatal and postnatal periods. J Comp Neurol 301:365-381. CrossRef Medline

Anders S, Pyl PT, Huber W (2015) HTSeq-a Python framework to work with high-throughput sequencing data. Bioinformatics 31:166-169. CrossRef Medline

Arand J, Spieler D, Karius T, Branco MR, Meilinger D, Meissner A, Jenuwein $\mathrm{T}$, Xu G, Leonhardt H, Wolf V, Walter J (2012) In vivo control of CpG and non-CpG DNA methylation by DNA methyltransferases. PLoS Genet 8:e1002750. CrossRef Medline

Atladóttir HO, Thorsen P, Østergaard L, Schendel DE, Lemcke S, Abdallah M, Parner ET (2010) Maternal infection requiring hospitalization during pregnancy and autism spectrum disorders. J Autism Dev Disord 40: 1423-1430. CrossRef Medline

Bayer SA (1980) Development of the hippocampal region in the rat. II. Morphogenesis during embryonic and early postnatal life. J Comp Neurol 190:115-134. CrossRef Medline

Bock C (2012) Analysing and interpreting DNA methylation data. Nat Rev Genet 13:705-719. CrossRef Medline

Bock C, Beerman I, Lien WH, Smith ZD, Gu H, Boyle P, Gnirke A, Fuchs E, Rossi DJ, Meissner A (2012) DNA methylation dynamics during in vivo differentiation of blood and skin stem cells. Mol Cell 47:633-647. CrossRef Medline

Campbell K (2003) Dorsal-ventral patterning in the mammalian telencephalon. Curr Opin Neurobiol 13:50-56. CrossRef Medline

Chen J, Kwon CH, Lin L, Li Y, Parada LF (2009) Inducible site-specific recombination in neural stem/progenitor cells. Genesis 47:122-131. CrossRef Medline

Cicchetti D, Toth SL (2005) Child maltreatment. Annu Rev Clin Psychol 1:409-438. CrossRef Medline

Deacon TW, Pakzaban P, Isacson O (1994) The lateral ganglionic eminence is the origin of cells committed to striatal phenotypes: neural transplantation and developmental evidence. Brain Res 668:211-219. CrossRef Medline

Do Rego JL, Seong JY, Burel D, Leprince J, Luu-The V, Tsutsui K, Tonon MC, Pelletier G, Vaudry H (2009) Neurosteroid biosynthesis: enzymatic pathways and neuroendocrine regulation by neurotransmitters and neuropeptides. Front Neuroendocrinol 30:259-301. CrossRef Medline

Eden A, Gaudet F, Waghmare A, Jaenisch R (2003) Chromosomal instability and tumors promoted by DNA hypomethylation. Science 300:455. CrossRef Medline

Ericson J, Muhr J, Placzek M, Lints T, Jessell TM, Edlund T (1995) Sonic hedgehog induces the differentiation of ventral forebrain neurons: a common signal for ventral patterning within the neural tube. Cell 81:747-756. CrossRef Medline

Fritz EL, Papavasiliou FN (2010) Cytidine deaminases: AIDing DNA demethylation? Genes Dev 24:2107-2114. CrossRef Medline

Galceran J, Miyashita-Lin EM, Devaney E, Rubenstein JL, Grosschedl R (2000) Hippocampus development and generation of dentate gyrus granule cells is regulated by LEF1. Development 127:469-482. Medline

Gerdeman GL, Ronesi J, Lovinger DM (2002) Postsynaptic endocannabinoid release is critical to long-term depression in the striatum. Nat Neurosci 5:446-451. Medline

Grove EA, Tole S (1999) Patterning events and specification signals in the developing hippocampus. Cereb Cortex 9:551-561. CrossRef Medline

Gu H, Smith ZD, Bock C, Boyle P, Gnirke A, Meissner A (2011) Preparation of reduced representation bisulfite sequencing libraries for genome-scale DNA methylation profiling. Nat Protoc 6:468-481. CrossRef Medline

Gutierrez-Arcelus M, Lappalainen T, Montgomery SB, Buil A, Ongen H, Yurovsky A, Bryois J, Giger T, Romano L, Planchon A, Falconnet E, Bielser D, Gagnebin M, Padioleau I, Borel C, Letourneau A, Makrythanasis P, Guipponi M, Gehrig C, Antonarakis SE, et al. (2013) Passive and active DNA methylation and the interplay with genetic variation in gene regulation. Elife 2:e00523. CrossRef Medline

Hahn MA, Qiu R, Wu X, Li AX, Zhang H, Wang J, Jui J, Jin SG, Jiang Y, Pfeifer GP, Lu Q (2013) Dynamics of 5-hydroxymethylcytosine and chromatin marks in Mammalian neurogenesis. Cell Rep 3:291-300. CrossRef Medline

Harris RA, Wang T, Coarfa C, Nagarajan RP, Hong C, Downey SL, Johnson BE, Fouse SD, Delaney A, Zhao Y, Olshen A, Ballinger T, Zhou X, Forsberg KJ, Gu J, Echipare L, O'Geen H, Lister R, Pelizzola M, Xi Y, et al. (2010) Comparison of sequencing-based methods to profile DNA methylation and identification of monoallelic epigenetic modifications. Nat Biotechnol 10:1097-1105. CrossRef Medline

Hirabayashi Y, Gotoh Y (2010) Epigenetic control of neural precursor cell fate during development. Nat Rev 11:377-388. CrossRef

Horton S, Meredith A, Richardson JA, Johnson JE (1999) Correct coordination of neuronal differentiation events in ventral forebrain requires the bHLH factor MASH1. Mol Cell Neurosci 14:355-369. CrossRef Medline

Jiang Y, Matevossian A, Huang HS, Straubhaar J, Akbarian S (2008) Isolation of neuronal chromatin from brain tissue. BMC Neurosci 9:42. CrossRef Medline

Jones PA (2012) Functions of DNA methylation: islands, start sites, gene bodies and beyond. Nat Rev Genet 13:484-492. CrossRef Medline

Kamiya D, Banno S, Sasai N, Ohgushi M, Inomata H, Watanabe K, Kawada M, Yakura R, Kiyonari H, Nakao K, Jakt LM, Nishikawa S, Sasai Y (2011) Intrinsic transition of embryonic stem-cell differentiation into neural progenitors. Nature 470:503-509. CrossRef Medline

Kaneda M, Okano M, Hata K, Sado T, Tsujimoto N, Li E, Sasaki H (2004) Essential role for de novo DNA methyltransferase Dnmt3a in paternal and maternal imprinting. Nature 429:900-903. CrossRef Medline

Kim D, Pertea G, Trapnell C, Pimentel H, Kelley R, Salzberg SL (2013) 
TopHat2: accurate alignment of transcriptomes in the presence of insertions, deletions and gene fusions. Genome Biol 14:R36. CrossRef Medline

Kohli RM, Zhang Y (2013) TET enzymes, TDG and the dynamics of DNA demethylation. Nature 502:472-479. CrossRef Medline

Li T, Yang D, Li J, Tang Y, Yang J, Le W (2015) Critical role of Tet3 in neural progenitor cell maintenance and terminal differentiation. Mol Neurobiol 51:142-154. CrossRef Medline

Lister R, Pelizzola M, Dowen RH, Hawkins RD, Hon G, Tonti-Filippini J, Nery JR, Lee L, Ye Z, Ngo QM, Edsall L, Antosiewicz-Bourget J, Stewart R, Ruotti V, Millar AH, Thomson JA, Ren B, Ecker JR (2009) Human DNA methylomes at base resolution show widespread epigenomic differences. Nature 462:315-322. CrossRef Medline

Lister R, Mukamel EA, Nery JR, Urich M, Puddifoot CA, Johnson ND, Lucero J, Huang Y, Dwork AJ, Schultz MD, Yu M, Tonti-Filippini J, Heyn H, Hu S, Wu JC, Rao A, Esteller M, He C, Haghighi FG, Sejnowski TJ, et al. (2013) Global epigenomic reconfiguration during mammalian brain development. Science 341:1237905. CrossRef Medline

Liu B, Zupan B, Laird E, Klein S, Gleason G, Bozinoski M, Gal Toth J, Toth M (2014) Maternal hematopoietic TNF, via milk chemokines, programs hippocampal development and memory. Nat Neurosci 17:97-105. CrossRef Medline

Li J, Harris RA, Cheung SW, Coarfa C, Jeong M, Goodell MA, White LD, Patel A, Kang SH, Shaw C, Chinault AC, Gambin T, Gambin A, Lupski JR, Milosavljevic A (2012) Genomic hypomethylation in the human germline associates with selective structural mutability in the human genome. PLoS Genet 8:e1002692. CrossRef Medline

Malenka RC, Bear MF (2004) LTP and LTD: an embarrassment of riches. Neuron 44:5-21. CrossRef Medline

Matevossian A, Akbarian S (2008) Neuronal nuclei isolation from human postmortem brain tissue. J Vis Exp 20:pii:914. CrossRef Medline

McGowan PO, Sasaki A, Huang TC, Unterberger A, Suderman M, Ernst C, Meaney MJ, Turecki G, Szyf M (2008) Promoter-wide hypermethylation of the ribosomal RNA gene promoter in the suicide brain. PLoS One 3:e2085. CrossRef Medline

Mohn F, Weber M, Rebhan M, Roloff TC, Richter J, Stadler MB, Bibel M, Schübeler D (2008) Lineage-specific polycomb targets and de novo DNA methylation define restriction and potential of neuronal progenitors. Mol Cell 30:755-766. CrossRef Medline

Moore LD, Le T, Fan G (2013) DNA methylation and its basic function. Neuropsychopharmacology 38:23-38. CrossRef Medline

Oh JE, Chambwe N, Klein S, Gal J, Andrews S, Gleason G, Shaknovich R, Melnick A, Campagne F, Toth M (2013) Differential gene body methylation and reduced expression of cell adhesion and neurotransmitter receptor genes in adverse maternal environment. Transl Psychiatry 3:e218. CrossRef Medline

Papaioannou VE, McBurney MW, Gardner RL, Evans MJ (1975) Fate of teratocarcinoma cells injected into early mouse embryos. Nature 258 : 70-73. CrossRef Medline

Ramsahoye BH, Biniszkiewicz D, Lyko F, Clark V, Bird AP, Jaenisch R (2000) Non-CpG methylation is prevalent in embryonic stem cells and may be mediated by DNA methyltransferase 3a. Proc Natl Acad Sci U S A 97: 5237-5242. CrossRef Medline

Robinson MD, McCarthy DJ, Smyth GK (2010) edgeR: a Bioconductor package for differential expression analysis of digital gene expression data. Bioinformatics 26:139-140. CrossRef Medline

Roth TL, Lubin FD, Funk AJ, Sweatt JD (2009) Lasting epigenetic influence of early-life adversity on the BDNF gene. Biol Psychiatry 65:760-769. CrossRef Medline
Seisenberger S, Andrews S, Krueger F, Arand J, Walter J, Santos F, Popp C, Thienpont B, Dean W, Reik W (2012) The dynamics of genome-wide DNA methylation reprogramming in mouse primordial germ cells. Mol Cell 48:849-862. CrossRef Medline

Seisenberger S, Peat JR, Hore TA, Santos F, Dean W, Reik W (2013) Reprogramming DNA methylation in the mammalian life cycle: building and breaking epigenetic barriers. Philos Trans R Soc Lond B Biol Sci 368: 20110330. CrossRef Medline

Smith ZD, Chan MM, Mikkelsen TS, Gu H, Gnirke A, Regev A, Meissner A (2012) A unique regulatory phase of DNA methylation in the early mammalian embryo. Nature 484:339-344. CrossRef Medline

Song Q, Decato B, Hong EE, Zhou M, Fang F, Qu J, Garvin T, Kessler M, Zhou J, Smith $\mathrm{AD}$ (2013) A reference methylome database and analysis pipeline to facilitate integrative and comparative epigenomics. PLoS One 8:e81148. CrossRef Medline

Sonnino S, Mauri L, Chigorno V, Prinetti A (2007) Gangliosides as components of lipid membrane domains. Glycobiology 17:1R-13R. Medline

Stadler MB, Murr R, Burger L, Ivanek R, Lienert F, Schöler A, van Nimwegen E, Wirbelauer C, Oakeley EJ, Gaidatzis D, Tiwari VK, Schübeler D (2011) DNA-binding factors shape the mouse methylome at distal regulatory regions. Nature 480:490-495. CrossRef Medline

Tepper JM, Bolam JP (2004) Functional diversity and specificity of neostriatal interneurons. Curr Opin Neurobiol 14:685-692. CrossRef Medline

Thurman RE, Rynes E, Humbert R, Vierstra J, Maurano MT, Haugen E, Sheffield NC, Stergachis AB, Wang H, Vernot B, Garg K, John S, Sandstrom R, Bates D, Boatman L, Canfield TK, Diegel M, Dunn D, Ebersol AK, Frum T, et al. (2012) The accessible chromatin landscape of the human genome. Nature 489:75-82. CrossRef Medline

Varley KE, Gertz J, Bowling KM, Parker SL, Reddy TE, Pauli-Behn F, Cross MK, Williams BA, Stamatoyannopoulos JA, Crawford GE, Absher DM, Wold BJ, Myers RM (2013) Dynamic DNA methylation across diverse human cell lines and tissues. Genome Res 23:555-567. CrossRef Medline

Wichterle H, Turnbull DH, Nery S, Fishell G, Alvarez-Buylla A (2001) In utero fate mapping reveals distinct migratory pathways and fates of neurons born in the mammalian basal forebrain. Development 128: 3759-3771. Medline

Wilson SW, Rubenstein JL (2000) Induction and dorsoventral patterning of the telencephalon. Neuron 28:641-651. CrossRef Medline

Wu H, Coskun V, Tao J, Xie W, Ge W, Yoshikawa K, Li E, Zhang Y, Sun YE (2010) Dnmt3a-dependent nonpromoter DNA methylation facilitates transcription of neurogenic genes. Science 329:444-448. CrossRef Medline

Xie W, Barr CL, Kim A, Yue F, Lee AY, Eubanks J, Dempster EL, Ren B (2012) Base-resolution analyses of sequence and parent-of-origin dependent DNA methylation in the mouse genome. Cell 148:816-831. CrossRef Medline

Yehuda R, Bell A, Bierer LM, Schmeidler J (2008) Maternal, not paternal, PTSD is related to increased risk for PTSD in offspring of Holocaust survivors. J Psychiatr Res 42:1104-1111. CrossRef Medline

Yun K, Potter S, Rubenstein JL (2001) Gsh2 and Pax6 play complementary roles in dorsoventral patterning of the mammalian telencephalon. Development 128:193-205. Medline

Ziller MJ, Müller F, Liao J, Zhang Y, Gu H, Bock C, Boyle P, Epstein CB, Bernstein BE, Lengauer T, Gnirke A, Meissner A (2011) Genomic distribution and inter-sample variation of non-CpG methylation across human cell types. PLoS Genet 7:e1002389. CrossRef Medline 